\title{
Growth of surface-breaching normal faults as a three-dimensional fracturing process
}

\author{
J. Ole Kaven*, Stephen J. Martel \\ University of Hawaii, Hawaii, USA \\ Received 17 February 2007; received in revised form 17 April 2007; accepted 29 May 2007 \\ Available online 27 June 2007
}

\begin{abstract}
Structures along the Hopena normal fault of the Koae fault system (KFS) on Kilauea volcano, Hawaii, provide a record of fault propagation in three dimensions. This fault displays (1) a breached monocline along the scarp; (2) a belt of discontinuous echelon fractures along the scarp and past its end; (3) a belt of discontinuous fractures on the footwall; (4) buckles at the base of the scarp; and (5) a belt of discontinuous fractures on the hangingwall that converges towards the end of the fault trace. Solid mechanics analyses show that this ensemble can be accounted for by the tipline of a normal fault propagating up towards the surface (accompanied by antithetic fracturing), then intersecting it and propagating laterally. Normal fault propagation down from the surface cannot account for the observed structures. Lateral slip occurs along some fractures as a result of local stress changes associated with fault propagation. Discontinuous fractures at the surface form early above a blind normal fault and continue to develop as a normal fault propagates laterally. Linkage of the fractures to the fault produces a fault with an irregular trace. The discontinuous, irregular character of normal fault traces over a broad range of scale is an inevitable consequence of three-dimensional fault growth. (C) 2007 Elsevier Ltd. All rights reserved.
\end{abstract}

Keywords: Faults; Fractures; Mechanical modeling; Basalt

\section{Introduction}

Normal fault traces on maps characteristically are irregular and discontinuous (Willemse, 1997; Crider and Pollard, 1998). Most studies of normal fault growth, however, have tended to focus on fault growth in cross section (e.g., MacDonald, 1957; Gudmundsson, 1987; Opheim and Gudmundsson, 1989; Gudmundsson and Bäckström, 1991; Acocella et al., 2003; Cartwright and Mansfield, 1998; Grant and Kattenhorn, 2004; Martel and Langley, 2006). These studies and others contribute to our understanding of how normal faults grow, but they are essentially two-dimensional and thus inherently unable to bear on certain three-dimensional matters, such as deformation at the ends of normal faults and fault propagation

\footnotetext{
* Corresponding author. Stanford University, Department of Geological \& Environmental Sciences, Braun Hall, Building 320, 450 Serra Mall, Stanford, CA 95110, USA.

E-mail address: kaven@pangea.stanford.edu (J.O. Kaven).
}

along strike. Recently, a series of investigators have addressed the linkage of echelon traces of normal faults (e.g., Peacock and Sanderson, 1996; Crider and Pollard, 1998; Kattenhorn and Pollard, 2001; Peacock and Parfitt, 2002; White and Crider, 2006). A central issue that has yet to be squarely addressed is how the discontinuous surface structure along normal faults is established in the first place.

We investigate the discontinuous structure along a well exposed normal fault in an active fault system to understand how the fault propagated along dip and along strike in three dimensions. We combine our large-scale mapping (Fig. 1) and mechanical analyses in our investigation.

We begin by describing the structure near the end of the Hopena fault, a normal fault in the Koae fault system (KFS) on the island of Hawaii (Fig. 1). We then test different scenarios for how the fault might have propagated by modeling three-dimensional elastic displacement and stress fields around a normal fault. The displacement fields illuminate whether the fault grew up to the surface or down from it. The stress fields 


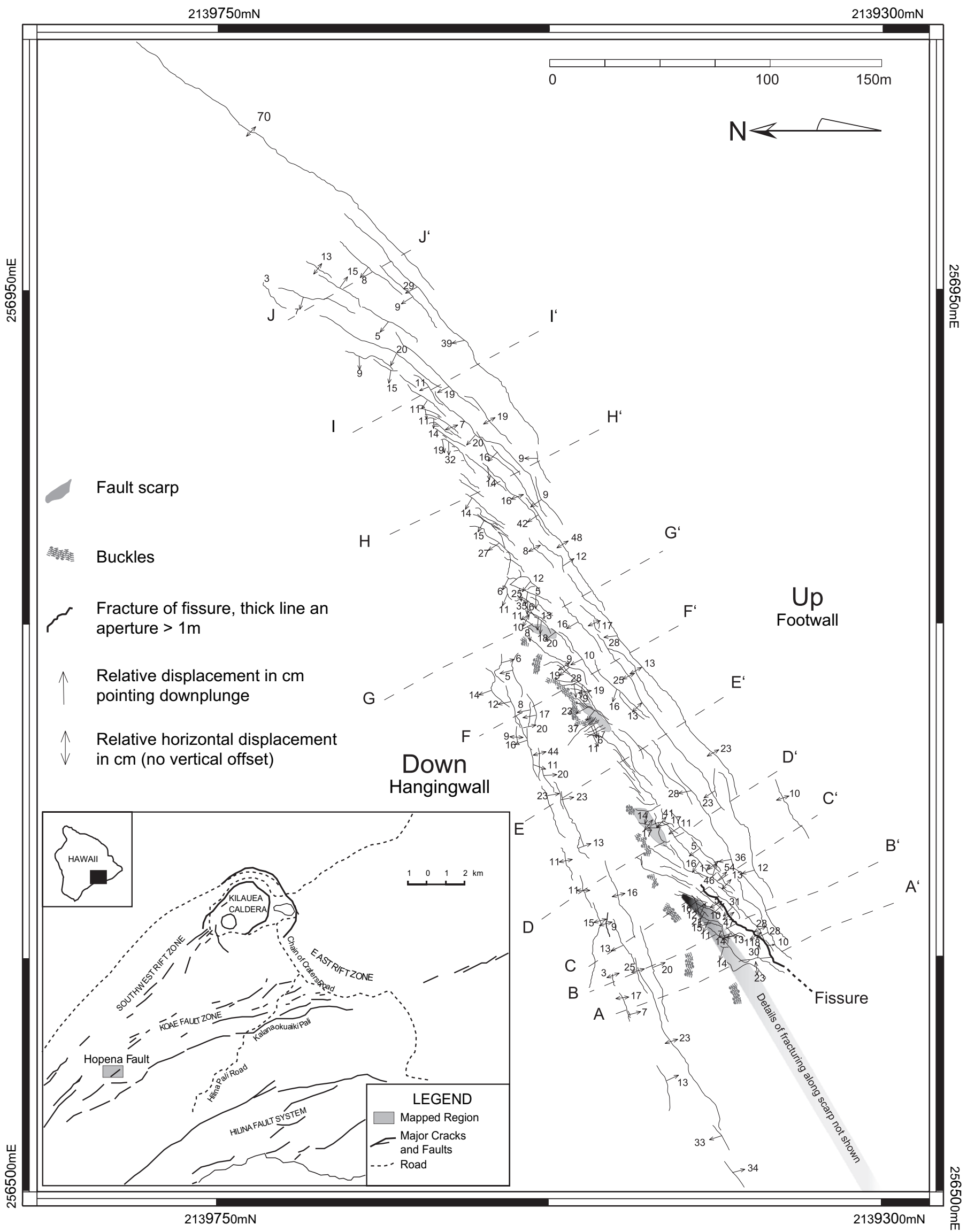

Fig. 1. Structural map of the northern fork of the Hopena Fault. Inset map modified from Martel and Langley (2006). 
help in understanding the location, orientation, and style of the observed structures along fault strike.

\section{Field observations}

\subsection{Koae fault system (KFS)}

The KFS traverses Kilauea's south flank (Fig. 1, inset) between the east and southwest rift zones (Duffield, 1975). The north edge of the KFS lies $\sim 4 \mathrm{~km}$ south of Kilauea caldera. The Kalanaokuaiki fault marks the southernmost extent of the KFS. It is the longest of the KFS faults. The KFS faults generally dip to the north. They feature prominent fissures along fault footwalls, buckles at the scarp bases, and finer fractures on the hanging walls (Duffield, 1975; Martel and Langley, 2006).

Pahoehoe basalt flows 400-750 years old (Wolfe and Morris, 1996) that dip gently to the south (Duffield, 1975) form most of the ground surface cut by the KFS. Historic lava flows and vegetation obscure the ends of many faults in the eastern part of the KFS. A 1974 lava flow covered the western end of several faults in the KFS (Pollard et al., 1983), including the western end of the Hopena fault (Fig. 1, inset), but its eastern end was not covered. Structural details that are superbly displayed there (Fig. 1) are obscured along most of the faults of the KFS. Also, unlike many neighboring faults, the eastern end of the Hopena fault is fairly distinct. The setting of the eastern end of the Hopena fault makes it well suited for our study of fault propagation.

\subsection{Hopena fault}

The trace of the Hopena fault is $\sim 4 \mathrm{~km}$ long and has an overall trend of $\mathrm{S} 62^{\circ} \mathrm{W}$ (Fig. 1, inset). Its scarp reaches a maximum height of 7-10 $\mathrm{m}$ along the central portion of its trace. The fault forks at its eastern end. The northern fork continues at the general strike of the Hopena fault. The southern fork curves to the south, merging at an acute angle with the
Kalanaokuaiki fault. Vegetation is sparse in this portion of the KFS, and does not obscure the fault (Fig. 2). Low-lying areas along the hanging wall are covered by ash no thicker than $30 \mathrm{~cm}$.

We divide the eastern end of the northern fork trace into three segments (Figs. 1 and 2). The westernmost segment has a continuous scarp that reaches a maximum height of $\sim 6 \mathrm{~m}$ (Figs. 1 and 3, profiles $\mathrm{A}-\mathrm{A}^{\prime}$ to $\mathrm{C}-\mathrm{C}^{\prime}$ ). Along this segment, rubble accumulates at the base of the scarp, and the surface of the hanging wall slopes towards the fault trace. The central segment has a fractured, faceted monocline with a steep central limb and a discontinuous scarp (Figs. 1 and 3, profiles $\mathrm{C}-\mathrm{C}^{\prime}$ to $\mathrm{G}-\mathrm{G}^{\prime}$ ). Profile $\mathrm{G}-\mathrm{G}^{\prime}$ marks the east end of the scarp. To the east of this profile the throw drops to less than $3 \mathrm{~m}$ and individual fractures accommodate dip-slip of less than $50 \mathrm{~cm}$. The easternmost segment displays a fractured monocline that becomes progressively flatter to the east (Figs. 1 and 3, profiles $\mathrm{H}-\mathrm{H}^{\prime}$ to $\mathrm{J}-\mathrm{J}^{\prime}$ ).

Three belts of steeply dipping fractures accompany the fault trace (Fig. 1). The first is located on the footwall (south of the fault). The second is along the fault scarp and east of it. The third is on the hanging wall. The boundary between the footwall fissures and the scarp fractures is indistinct, whereas the hanging wall fractures are distinct from the scarp fractures.

The footwall fractures have the longest trace lengths and greatest apertures. Along the western and central segments (Fig. 1), the footwall fractures strike ENE, essentially parallel to the fault, and open almost purely orthogonal to fracture strike (Fig. 4a). Along the eastern segment, the footwall fractures strike northeast (Fig. 1) and open to the northwest (Fig. 4a).

The belt extending along and past the scarp contains rightstepping echelon fractures (Fig. 1). The fractures generally are spaced 1-2 $\mathrm{m}$ apart and divide the scarp into a series of northeast-trending ramps (Figs. 1 and 2, left end). These ramps are broken into blocks by smaller fractures with varying strikes. The scarp fractures in the western and central segments generally strike northeast (Fig. 4b) and tend to have longer traces

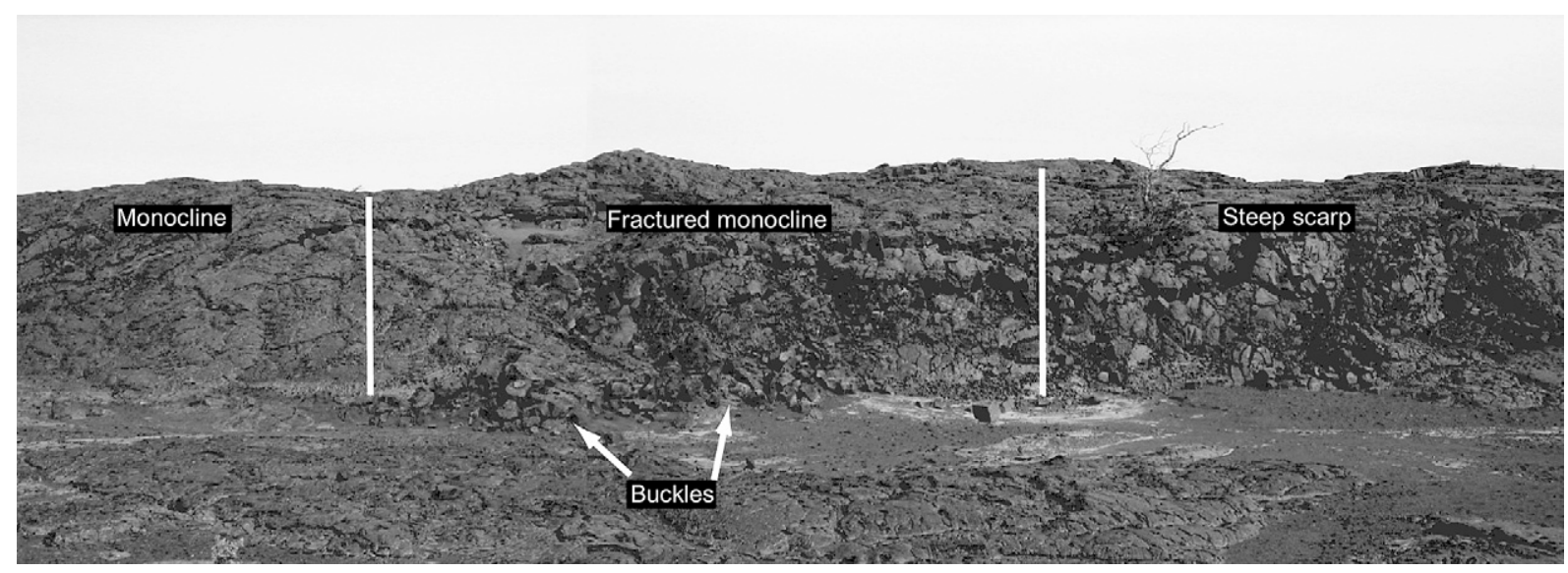

Fig. 2. Composite photograph taken from the north looking south to the fault scarp of the Hopena fault. Proceeding from west (right) to east (left), the scarp gradually changes from a steep scarp to a fractured monocline to a monoclinal flexure. The photograph extends about $40 \mathrm{~m}$ from profile $\mathrm{D}-\mathrm{D}^{\prime}$ to $\mathrm{E}-\mathrm{E}^{\prime}$ in Fig. 1. At profile $\mathrm{D}-\mathrm{D}^{\prime}$ the scarp is $\sim 5 \mathrm{~m}$ tall. 


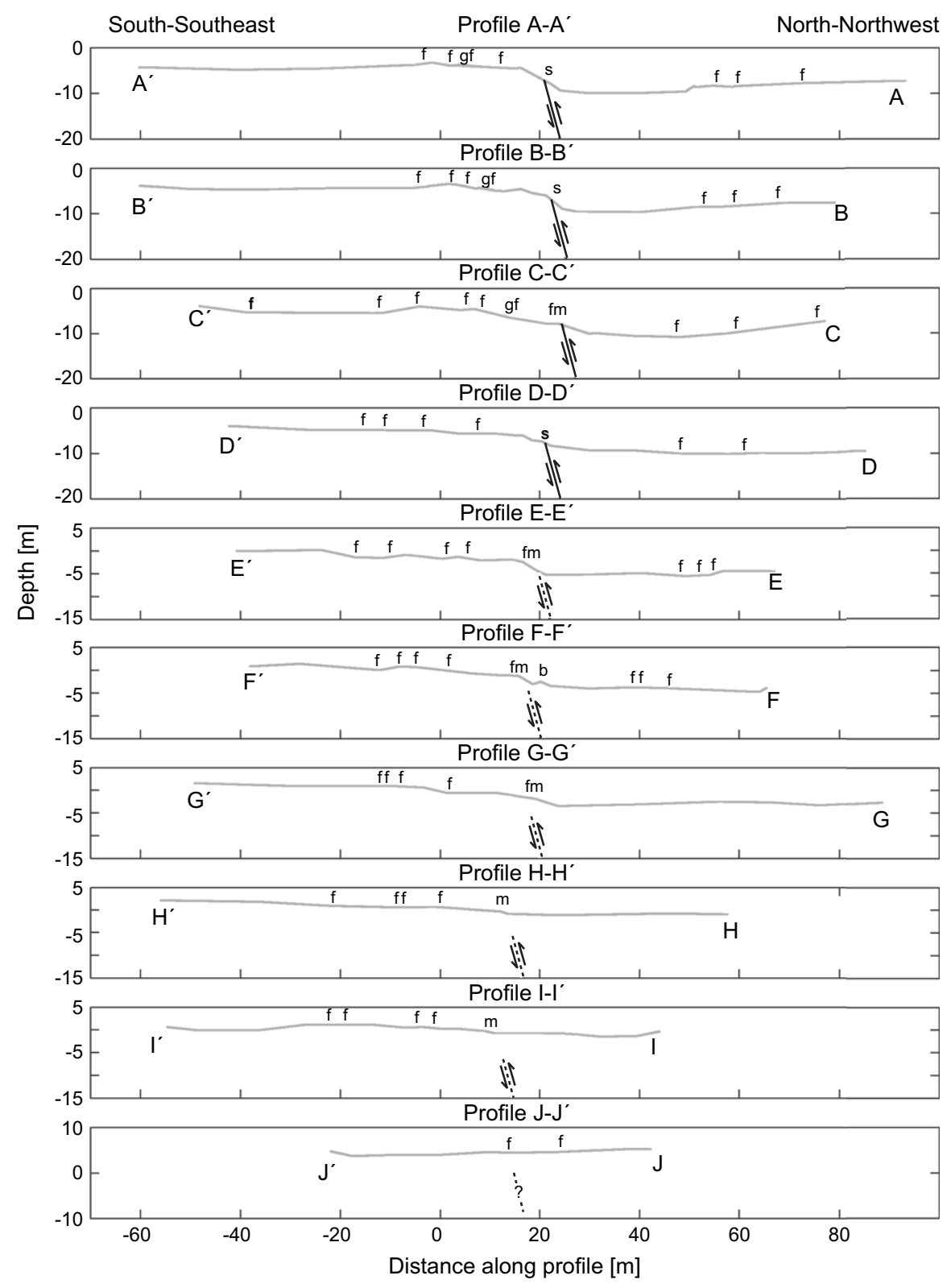

Fig. 3. Topographic profiles across the North Fork of the Hopena Fault from west-southwest (top profile, A- $\mathrm{A}^{\prime}$ ) to east-northeast (bottom profile, $\mathrm{J}-\mathrm{J}^{\prime}$ ). The southsoutheast ends of the profiles are to the left. Profile locations are shown in Fig. 1. Faults are shown in solid lines where a scarp exists and dashed where inferred at depth. Labeled features: fractures (f), gaping fissures (gf), scarp (s), fractured monocline (fm), monocline (m), and buckles (b).

than those in the eastern segment, which strike closer to NNE (Fig. 4c).

Along most of the scarp fractures, the northern fracture walls are dropped down with respect to the southern walls, consistent with the sense of throw on the fault. The relative horizontal displacement across the most prominent scarp fractures is primarily orthogonal to fracture strike but does have a strike slip component (Fig. $4 \mathrm{~b}, \mathrm{c}$ ). West of profile $\mathrm{E}-\mathrm{E}^{\prime}$ the sense of slip is inconsistent. Both right-lateral and left-lateral slip occurs (Fig. 4b), but it is generally an order of magnitude smaller than the aperture. East of profile $\mathrm{E}-\mathrm{E}^{\prime}$, however, the strike-slip is consistently left-lateral (Fig. 4c) and generally is more than one-third of the aperture.
The belt of fractures on the hanging wall trends on average $\mathrm{N} 73^{\circ} \mathrm{E}$ and merges with the eastern end of the fault scarp at an acute angle near profile $\mathrm{G}-\mathrm{G}^{\prime}$ (Fig. 1). Fractures in the belt strike subparallel to the belt as a whole. Their relative displacement is primarily orthogonal to fracture strike (Fig. 4d), with apertures as large as $40 \mathrm{~cm}$.

Near the base of the fault scarp on the hanging-wall, the ground surface is buckled into several sharply hinged anticlines (Figs. 1-3 profile $\mathrm{F}-\mathrm{F}^{\prime}$ ). Some are fractured just at the hinge; others are highly fractured throughout. These buckles vary in length from 2 to $10 \mathrm{~m}$. They are generally 1-2 $\mathrm{m}$ wide and $0.5-1 \mathrm{~m}$ tall. The distance from the buckles to the base of the fault varies from 1 to $20 \mathrm{~m}$ and decreases to 

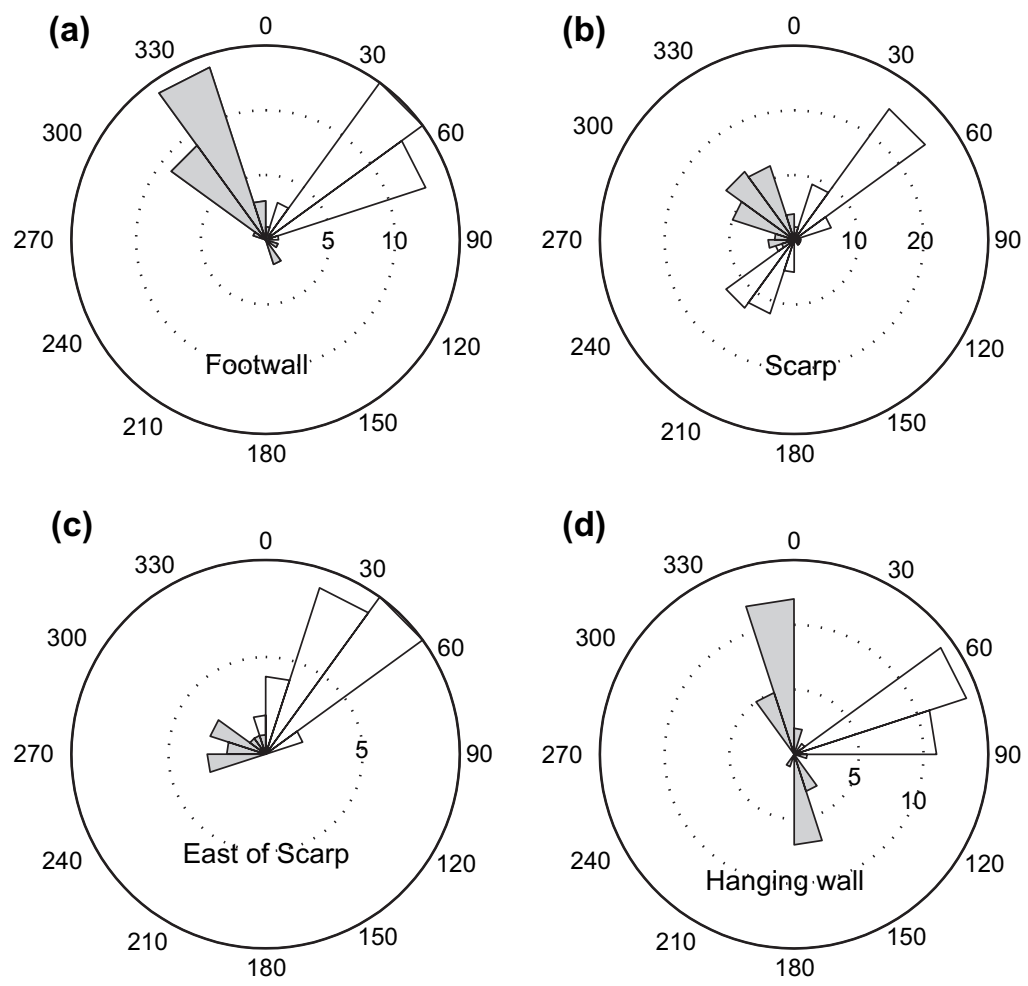

Fig. 4. Rose diagrams of fracture strike (white sectors) and trend of horizontal relative displacement (grey sectors). Fracture strikes are $90^{\circ}$ counter-clockwise from the fracture dip direction. Horizontal displacements are measured in the direction from the uplifted wall to the downdropped wall. The size of the sectors indicates the number of fractures (white) and number of displacement measurements (grey) in a range of orientations. (a) Fractures on the footwall. (b) Fractures at the scarp. (c) Fractures east of the scarp. (d) Fractures on the hanging wall.

the east. The trends of the buckle fold axes are highly variable. Even within a single buckle, the fold axis trend can change from southeast to northeast. Near the eastern end of the fault scarp, buckles are only 1-4 m north of the base of the scarp. Buckles do not occur past the east end of the fault scarp (profile $\mathrm{G}-\mathrm{G}$, Fig. 1), although the monocline does.

The structures along the Hopena fault resemble those $3 \mathrm{~km}$ to the northeast along the eastern end of the Ohale fault (Martel and Langley, 2005). The surface deformation and general fracture patterns also mirror those along the western end of the Kalanaokuaiki fault. The similar systematic patterns indicate that the deformation along the Hopena fault is representative of the KFS faults.

\section{Mechanical analysis of near-fault deformation}

To explain the process of deformation and, in particular, the fracturing, along the Hopena fault, we conducted a series of three-dimensional mechanical analyses. In these analyses we consider the fault to be contained in a homogeneous, isotropic, isothermal, linear elastic material. We evaluate the stress field for faults of increasing size and varying shape to gain insight into how the surface structures initiate and evolve as a fault grows. We first consider two general scenarios involving an isolated fault: (a) fault propagation down from the surface, and (b) fault propagation up to the surface. We then consider models with one fault and several secondary structures.

\subsection{Reference frame, ambient stress field, and boundary conditions}

In our reference frame, the $x_{1}$ axis parallels fault strike, $x_{2}$ is horizontal and perpendicular to fault strike, and $x_{3}$ is up (Fig. 5). We describe stresses in this reference frame, with tension being positive.

The ambient stress field on the south flank of Kilauea is complicated, being influenced by the buttress of Mauna Loa to the north and by two rift zones. The ambient stresses probably vary in time also as dikes intrude along the rift zones and earthquakes occur (Rubin and Pollard, 1987; Lipman et al., 1985). The dominant strike of opening mode fractures and normal faults to the WSW imply that ambient horizontal stress field is anisotropic, with the most compressive regional stress trending parallel to fracture strike and the most tensile stress trending normal to fault strike. We follow the suggestions of Swanson et al. (1976) and idealize the south flank as laterally unconstrained and set the ambient horizontal stress normal to fault strike to zero. This choice accounts for the fissures not growing unless the ambient stresses are perturbed, while allowing for modest tensile stress perturbations to trigger fissuring. A constant compressive (negative) stress of $1 \mathrm{MPa}$ is assigned parallel to the fault strike; this stress component does not affect fault slip and unless it is compressive we cannot account for the overall strike of fractures on the footwall of the fault. Increasing the fault-parallel compressive in our model would cause the predicted opening mode fractures 

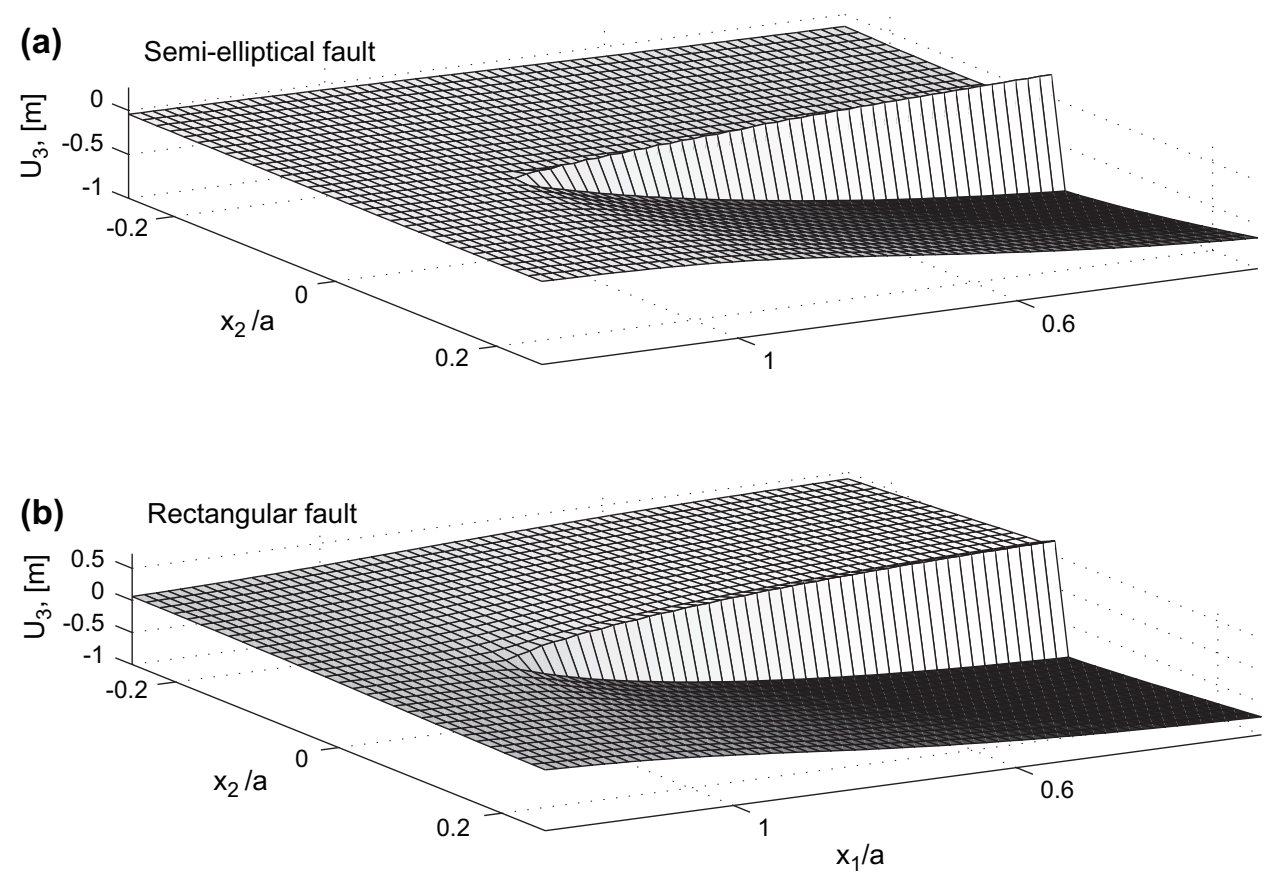

Fig. 5. Oblique view of modeled vertical surface displacements at the ground surface for a fault that extends down from the surface: (a) semi-elliptical fault, (b) rectangular fault. Monoclinal flexure left of the fault scarp is weak.

to strike even more nearly parallel to the fault than they do now. The vertical normal stresses due to gravity vary linearly with depth. The principal ambient stress thus is:

$\sigma_{33}=\rho g x_{3}$

$\sigma_{22}=-1 \mathrm{MPa}$

$\sigma_{11}=0$

In the above equations $g$ is the gravitational acceleration, and $\rho$ is rock density. Values of the material parameters are $\rho=2300 \mathrm{~kg} \mathrm{~m}^{-} 3, \nu$ (Poisson's ratio) $=0.25$, and $E$ (Young's modulus) $=5 \mathrm{GPa}$ (Martel and Langley, 2006).

The fault walls are prescribed to be free of shear tractions and to remain in contact during slip. This maximizes the slip we calculate and yields the maximum stress perturbation in the surrounding rock. The results here thus serve as an end member in the spectrum of possible slip behaviors.

\subsection{Boundary element method}

The analyses are carried out with Poly3D, a three-dimensional boundary element method (BEM) numerical code (Thomas, 1993). In this method, a fault or fracture surface is divided into contiguous polygonal elements, each of which accommodates a constant amount of relative displacement. The displacement discontinuities across all elements are found by solving a system of linear equations that describes the influence of the elements on one another and that simultaneously satisfies the given boundary conditions. Tests on simple fault shapes for which analytical solutions exist show that Poly3D reproduces analytical results to within a few percent (Crider and Pollard, 1998).

\subsection{Analysis for an isolated fault}

We model the displacements and stresses to account for (a) the deflection of the ground surface, and (b) the location, orientation, and kinematics of fractures and buckles along the fault trace. We consider planar faults that dip at $75^{\circ}$; fault parameter inversions using topographic data for the Hopena fault favor this dip over dips of $65^{\circ}$ or $85^{\circ}$ (Kaven, 2004).

\subsubsection{Downward fault propagation}

The fault tipline geometries we model to simulate fault propagation down from the surface reflect choices of previous investigators. Faults that extend down from the surface have been idealized as semi-circular (Crider and Pollard, 1998), rectangular (Grant and Kattenhorn, 2004), or truncated ellipses (Nicol et al., 1996; White and Crider, 2006). We examine semi-elliptical and rectangular geometries here. Common aspect ratios of elliptical faults in sedimentary rocks range from $b / a=1 / 8$ to $1 / 2$, where $b$ is the down-dip semi-axis length and $a$ is the along-strike semi-axis length (Nicol et al., 1996). Using these ratios as guides, we consider semielliptical and rectangular faults that have a constant aspect b/a ratio of $1 / 2$.

Fig. 5 shows the vertical displacement $\left(u_{3}\right)$ at the ground surface $\left(x_{3}=0\right)$ associated with semi-elliptical and rectangular faults that extend down from the surface. In both cases, the displacements are discontinuous at the fault trace (i.e., at $x_{2} / a=0$, $\left.\left|x_{1}\right|<a\right)$, are largest where the faults intersect the surface, and 
decay with distance from the fault. The surface is not monoclinally folded at the model scarp. Past the ends of the model fault traces, little ground flexure occurs. The main difference between the two profiles is that the throw at the surface tapers in a more linear fashion toward the fault end for the semielliptical fault (Fig. 5a) than the rectangular fault (Fig. 5b).

Fig. 6 shows the principal horizontal stresses in map view at the surface around the right half of the fault. Tensile stress concentrations occur near the ends of the fault trace for both semi-elliptical (Fig. 6b) and rectangular (Fig. 6e) fault geometries, but are stronger for the rectangular fault. This is consistent with the higher gradient in throw near the fault trace end for the rectangular fault (Fig. 5). Immediately adjacent to the fault trace the most tensile stresses are in fact compressive on both the footwall and hanging wall. On the footwall of both faults, the most tensile stress is generally either parallel or oblique to fault strike (Fig. 6b,e), even though the ambient most tensile stress is perpendicular to the fault. This means that slip on the fault has caused the principal stresses on the footwall to rotate by as much as $90^{\circ}$ about a vertical axis.

The two fault geometries tested are incapable of accounting for key observations. Neither produces a displacement field resembling the breached monocline along the Hopena fault. Along the fault trace on the model footwall, the most tensile stresses are in fact compressive (Fig. 6b,e); this is inconsistent with the numerous open footwall fractures that strike parallel

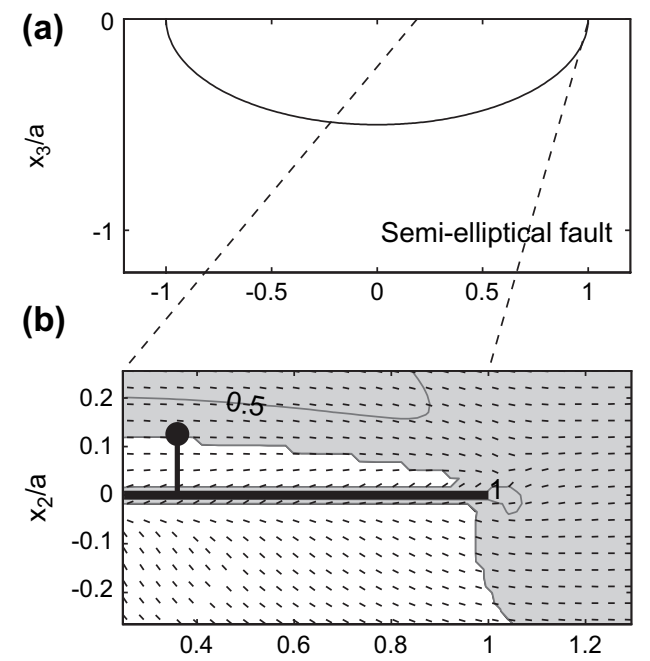

(c)

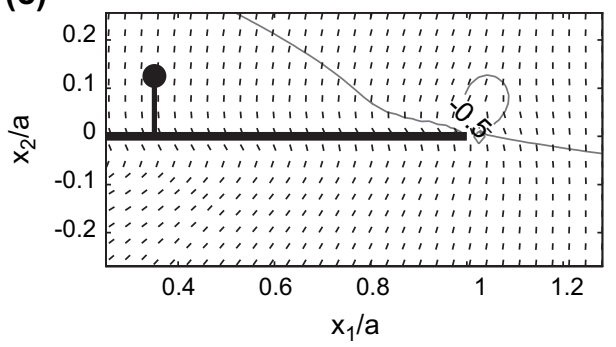

to the Hopena fault. The models for the normal faults that extend down from the surface also predict that if footwall fractures could somehow open that they would not parallel the fault; this too is inconsistent with the observations. The compressive stresses predicted on the hanging wall are inconsistent with the open fractures there, and their magnitudes are so low that they do not readily explain the buckles at the base of the fault scarp either (Martel and Langley, 2006). We thus reject the model that the Hopena fault nucleated at the surface and grew down from it.

\subsubsection{Fault propagation up to the surface}

We idealize a fault growing up from depth by a succession of geometries based on an ellipse: an ellipse when the fault is blind (does not intersect the surface), an ellipse with its tipline tangent to the ground surface at an intermediate stage, and an ellipse truncated by the surface when the fault breaches the surface where the fault tips propagate laterally along strike. Our choice of an ellipse as a "base shape" reflects the findings of Rippon (1985) that the tiplines of blind normal faults in nature tend to be roughly elliptical. We consider planar elliptical faults that also have a constant ratio of down-dip semi-axis length to along-strike semi-axis length of $1 / 2$ based on the findings of Nicol et al. (1996).

The vertical displacement field shows that a smooth monocline develops above a blind model fault (Fig. 7a), with the

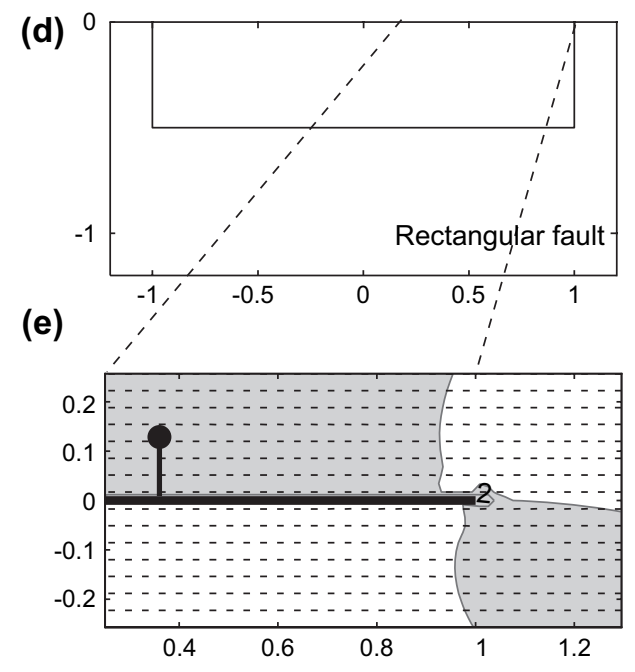

(f)

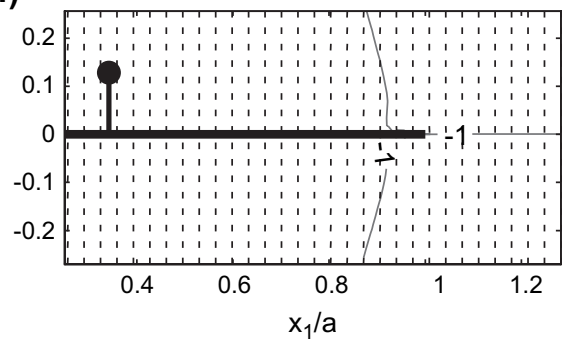

Fig. 6. Maps of modeled stress fields at the surface for faults that extend down from the surface, with stresses in dimensions of MPa. The top row shows the fault geometry. The middle row shows magnitudes of the most tensile stresses $\left(\sigma_{1}\right)$ and trajectories perpendicular to $\sigma_{1}$ (i.e., orientations of possible opening mode fractures). Gray indicates where $\sigma_{1}$ is tensile. The bottom row shows magnitudes of the most compressive stress $\left(\sigma_{3}\right)$, and trajectories perpendicular to $\sigma_{3}$ (i.e., orientations of possible buckles). Heavy lines mark fault scarps in the lower two rows, with the ball on the hanging wall. 
central limb becoming steeper as the fault tip approaches the surface (Fig. 7b). This shape is much more consistent with the shape of the Hopena scarp than that of Fig. 5. We conclude that the monoclinal shape of the Hopena fault reflects the propagation of a normal fault up to the surface rather than down from it.

Once the fault breaches the surface (Fig. 7c), the vertical displacements become discontinuous at the fault trace and the continuous monocline of Fig. $7 \mathrm{~b}$ disappears. A gentle monoclinal flexure past the end of the model fault trace in Fig. 7c dies out over a distance from the fault trace tip that is small relative to the half-length $a$. The displacement field in Fig. 7c has a small but abrupt step on the hanging wall near the end of the fault trace but otherwise resembles that of Fig. 5a. The disappearance of the monocline along the scarp once the model fault breaches the surface does not match our observations along the Hopena fault, but this does not cause us to reject our hypothesis that the Hopena fault grew up towards the surface. The abundance of fractures on the footwall demonstrates that substantial non-elastic deformation occurs on the footwall. We infer that this fracturing accounts to a large degree for why the monocline along the Hopena fault did not disappear once the fault breached the surface.

If the Hopena fault did grow up to the surface, then the stress distribution at the surface above a blind fault should provide insight into the fracturing along the Hopena scarp. Fig. 8b shows that a strong tensile stress concentration develops on the footwall $\left(x_{3} / a<0\right)$ near where the fault projects to the surface. This stress concentration intensifies and shifts closer to $x_{3}=0$ as the fault approaches the surface (Fig. 8e). Where the tensile stresses are highest on the footwall in Fig. 8b,e, the trajectories normal to the most tensile stress parallel the fault strike. These conditions favor the opening of footwall fractures that strike parallel to the fault. Elevated tensile stresses also extend along and to the positive side of $x_{2} / a=0$ (i.e., the region of the eventual fault scarp), and allow for fracturing there as well. The trajectories normal to the most tensile stress there are oblique to fault strike, trending as much as $45^{\circ}$ from the strike of the fault (Fig. 8b,e). Fractures oblique to fault strike thus would be expected to develop along the scarp, and such fractures are abundant in the field (Fig. 1). The model results also indicate that footwall fractures parallel to the fault trace and fault scarp fractures oblique to the fault trace could develop contemporaneously since tensile stresses are concentrated in both places. This is consistent with our observations that both sets of fractures occur together even where the central limb of the faultscarp monocline is less than a meter tall, both at the Hopena fault (Fig. 1) and at the Ohale fault (Martel and Langley, 2006).

On the hanging wall, a strong compressive stress concentration develops close to $x_{2} / a=0$ (Fig. 8c). This intensifies as the fault approaches the surface (Fig. 8f). The trajectories normal
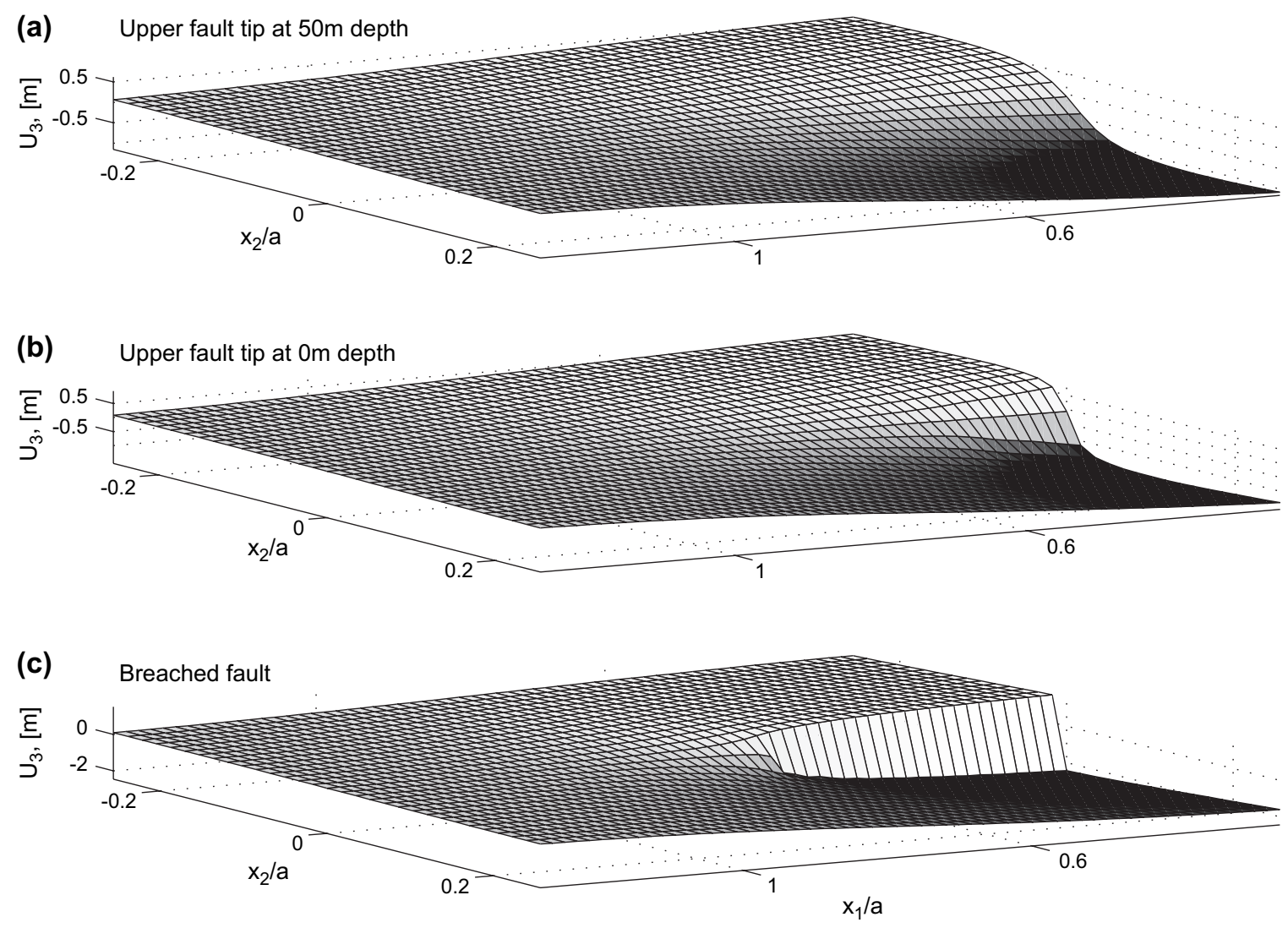

Fig. 7. Oblique view of modeled vertical surface displacements at the ground surface for an isolated model fault. (a) For a fault with upper tip at $50 \mathrm{~m}$. (b) For a fault with the upper tip tangential to the observation plane. (c) For a breached fault. See top row of Fig. 8 for fault geometries. Monoclinal flexure is more pronounced in (b) than in (a). 
to the most compressive stress there parallel the fault trace (Fig. 8c,f). These conditions favor the formation of buckles with axes parallel to the fault trace, consistent with our observations (Fig. 1). A compressive stress also parallels the fault trace, so buckles also could form locally with axes perpendicular to the fault trace.

The surficial stress pattern changes substantially once the fault breaches the surface (Fig. 8h,i). Surface stress concentrations shift towards the ends of the fault scarp and diminish substantially elsewhere along it. New fractures thus would be expected to open ahead of the advancing fault trace tip (i.e., on the developing scarp) once the fault breaches the surface. Based on the orientation of trajectories normal to the most tensile stress there, fractures on both the footwall and the scarp would both tend to strike obliquely to the fault, with the angle between the traces of the fractures on the scarp and the fault exceeding the angle between the fractures on the developing scarp and the fault (Fig. 9). As the fault trace tip advances (i.e., propagates laterally), the principal stresses rotate (Fig. 9b,c). In the case of Fig. 9c, this rotation would induce left-lateral slip along fractures striking parallel to the right-hand heavy tick. This is consistent with our observations of left-lateral slip along fault scarp fractures east of profile $\mathrm{E}-\mathrm{E}^{\prime}$ (Fig. 4c).

\subsubsection{Analysis for a fault and a footwall fissure}

Fractures that may open on the footwall when the fault is blind might be expected to close once the fault breached the surface based on modeling results showing that fault-normal compressive stresses then dominate the footwall (e.g., Fig. 6). Martel and Langley (2006) postulated that the fissures on the footwall are kept from closing, at least in part, by debris stoped from the fissure walls. Guided by the field observations and results from a blind isolated model fault (Fig. 8b), an open fissure is included in subsequent model runs. The fissure is represented by the lower half of an ellipse centered at $x_{2} / a=-25 \mathrm{~m}$. The fissure is $2.5 \mathrm{~km}$ long and extends from the surface to a depth of $200 \mathrm{~m}$. The length and location are consistent with our observations, and the depth is consistent with elastic model predictions of Martel and Langley (2006). The fissure is kept from closing by prescribing an opening mode relative displacement and its walls are set to be free of any shear tractions $\left(t_{1}=t_{2}=0\right)$. The scaled opening prescribed on the model fissure is consistent with $\sim 1.4 \mathrm{~m}$ maximum aperture of the fissure near the Hopena fault.

Model results for a fault with a nearby fissure resemble those for an isolated fault. The similarities are particularly apparent for the stress fields (compare Figs. 8 and 10). For blind faults, tensile stresses continue to dominate the footwall (Fig. 10b,e) and compressive stresses dominate the hanging wall (Fig. 10c,f). The magnitudes of the most compressive stresses on the hanging wall increase with the presence of the fissure. The opening of the footwall fissures thus enhances the tendency for buckling at the scarp base. The stress patterns for a breached fault with a footwall fissure (Fig. 10h,i) also resemble those for a breached fault without a footwall fissure (Fig. 8h,i). Stress concentrations in both cases shift to near (a)
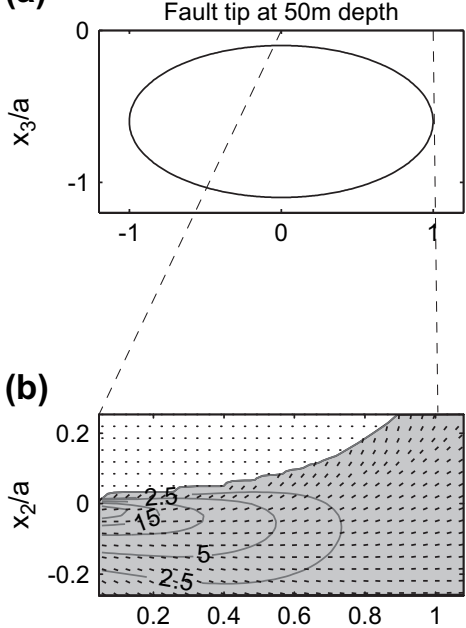

(c)

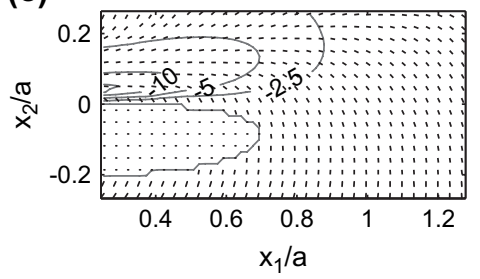

(d)
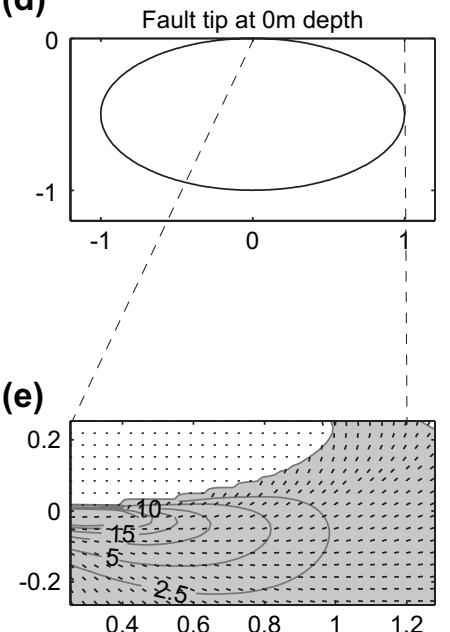

(f)

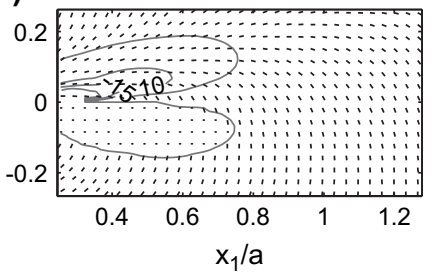

(g)
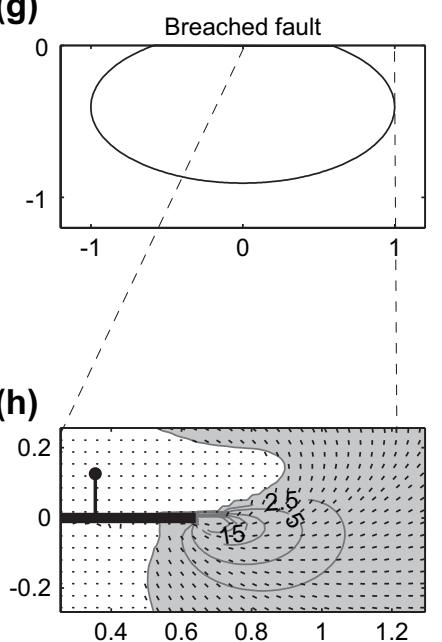

(i)

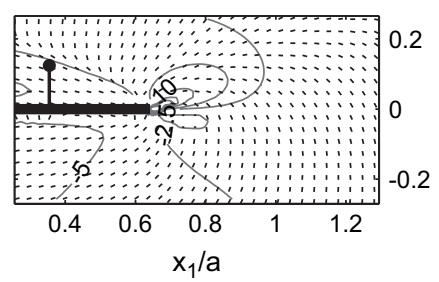

Fig. 8. Geometry of faults and maps of modeled stress fields at the surface near an isolated fault. Where the trajectories appear as does, the most tensile stress is vertical and equal to zero. Columns are arranged as in Fig. 6. 

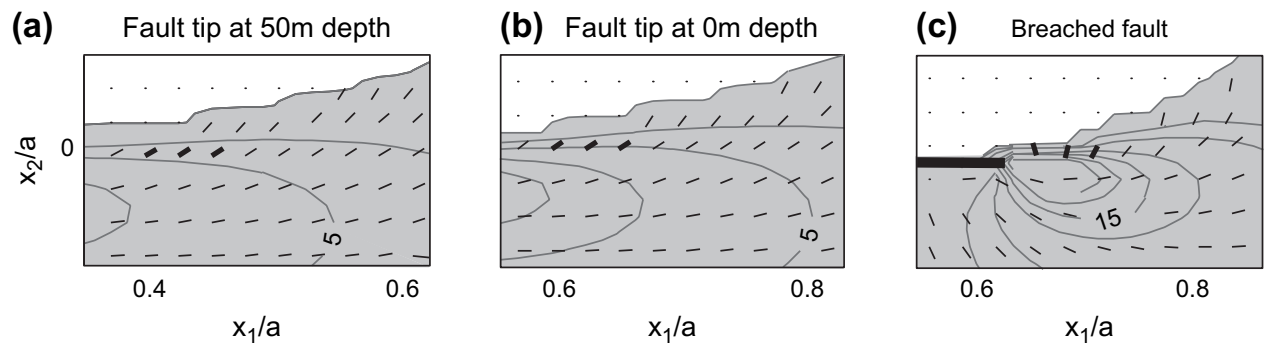

Fig. 9. Map view of tensile principal stresses, $\left(\sigma_{1}\right)$, and trajectories normal to the most tensile principal stress near $x_{2} / a=0$. These trajectories are proxies for orientations of possible opening-mode fractures. Thick trajectories indicate a subset of fractures that are representative of fractures observed near the scarp for faults at different depths. (a) Blind fault with its upper tip at a depth of $50 \mathrm{~m}$, (b) fault with the upper tip tangential to the free surface, (c) breached fault.

the end of the fault trace. The principal stress orientations during the successive stages of faulting also resemble those for the isolated fault. Thus, the sense of relative displacement on northeast-striking echelon fractures along the scarp will tend to be left-lateral along the eastern half of the fault whether or not footwall fissures are present.

The model containing a fault and nearby footwall fissure account for the surface warping, footwall fractures, echelon fracture pattern near the scarp, the sense of relative displacement at scarp fractures, and the formation of buckles near the scarp. The tendency for buckles to form at the base of the scarp is increased by the presence of the footwall fissure, as previously noted by Martel and Langley (2006).

\subsubsection{Analysis for a fault, a footwall fissure, and an antithetic fault}

The analyses to this point do not account for the hanging wall fractures. Martel and Langley (2006) showed that a large tensile stress concentration, and hence fracturing, can be anticipated near the upper tipline of a blind normal fault on the hanging wall in the subsurface. Antithetic fractures in the shallow subsurface have also been produced in scaled laboratory models of normal faults in clays (e.g., Cloos, 1968) and hemihydrate ("gypsum") powder (Holland et al., 2006), materials with an intrinsic tensile strength, and they are widespread in the Koae fault system (Duffield, 1975). Based on the experimental work and the mechanical results we have presented,

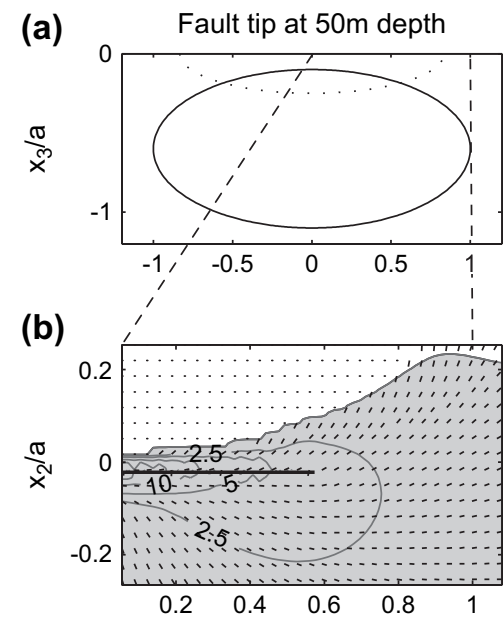

(e)

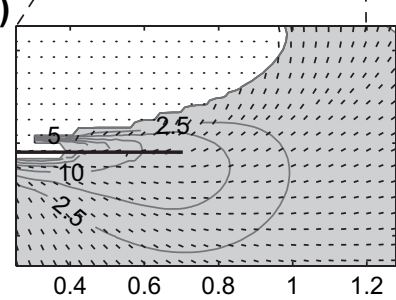

(c)

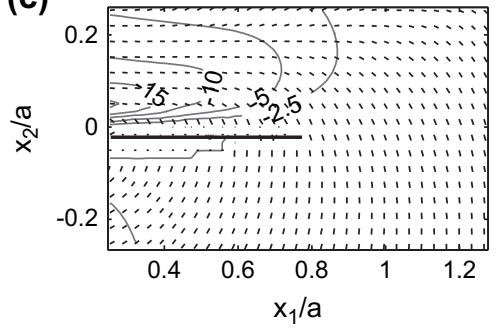

(f)

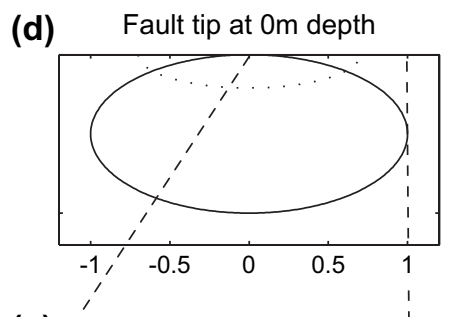

(g)

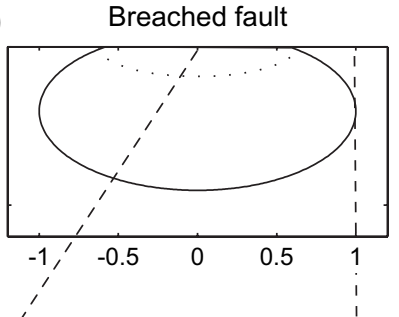

(h)
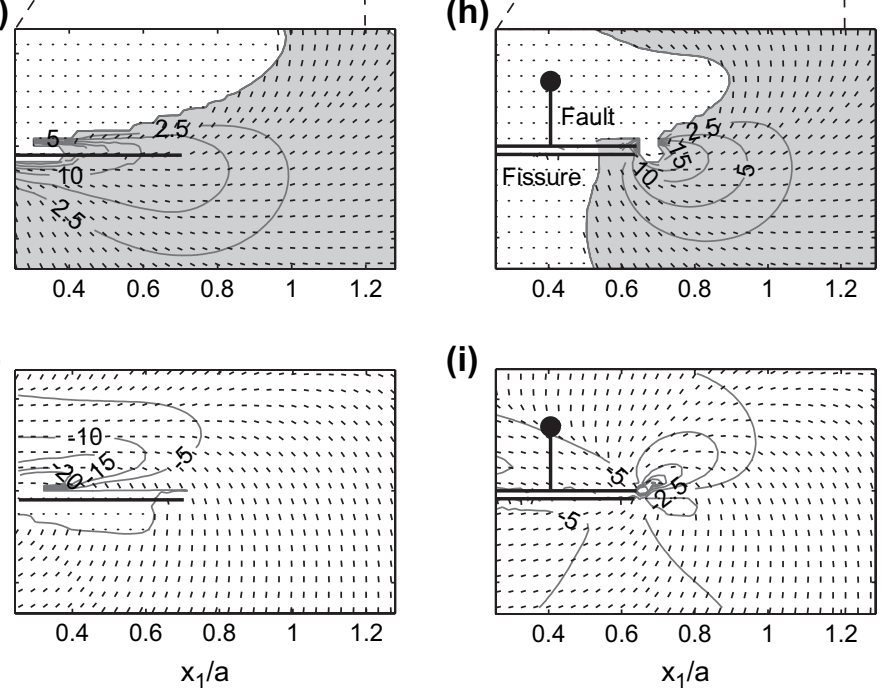

(i)

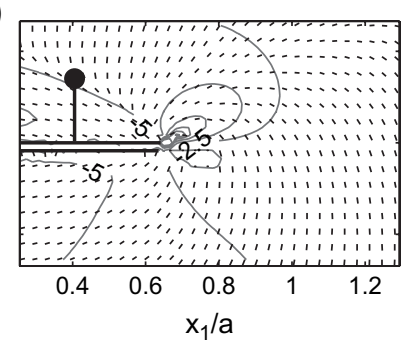

Fig. 10. Geometry of faults and maps of modeled stress fields at the surface near an isolated fault. Columns are arranged as in Fig. 6 . The location of the fissure is indicated by the dotted line. The fissure traces are indicated by a medium line. 
the predicted subsurface fractures would strike parallel to the fault and dip roughly perpendicular (i.e., antithetic) to it. These findings prompt a modification to the model for a fault growing up from depth: a blind antithetic fracture is included as a traction-free half-ellipse extending over $80 \%$, or $\sim 1 \mathrm{~km}$, of the length of the fault near the upper tipline. The main fault has a semi-major axis length of approximately $1700 \mathrm{~m}$, downdip width of $\sim 850 \mathrm{~m}$, and its upper tip is at $30 \mathrm{~m}$ depth. The antithetic fracture has a semi-major axis length of $\sim 500 \mathrm{~m}$ and a semi-minor axis length of $80 \mathrm{~m}$. The fracture strikes parallel to the fault and dips $40^{\circ}$, and its upper tip is at $40 \mathrm{~m}$ depth. This geometry yields a tensile concentration consistent with the location of fractures on the surface of the hanging wall. The model also includes a vertical footwall fissure with a semi-elliptical shape. Its semi-major axis is $1250 \mathrm{~m}$ long and it extends to a depth of $200 \mathrm{~m}$. The fissure is contained in the plane $x_{2}=-25 \mathrm{~m}$. This single model fissure represents what could be a series of fissures along a real fault. The exact dimensions of the inferred antithetic subsurface fracture and the footwall fissure are not well constrained based on the field observations, but as best we can tell the dimensions chosen are reasonable.

For the modified model with a blind antithetic fault (Fig. 11a), a tensile stress concentration arises on the hanging wall of the master fault close to the upper tip of the blind antithetic fracture (Fig. 11b). Trajectories perpendicular to $\sigma_{1}$ indicate that fractures that open at the surface would strike parallel to the fault. Between the center of the fault trace and its fault ends the magnitude of $\sigma_{1}$ decreases and the trajectories perpendicular to $\sigma_{1}$ bend subtly but distinctly towards the fault, $x_{1} / a=0.1-0.2$ (Fig. 11b).

The model of Fig. 11, which accounts for an antithetic fault at shallow depth, yields tensile stress fields consistent with the orientation of the belt of opening mode fractures on the hanging wall of the Hopena fault. The tensile stress concentration is farther away from the scarp than the compressive stress concentration of Fig. 8h,i and Fig. 10h,i that we associate with the buckles. Also note that the location and shape of the region of tensile principal stress in Fig. 11 mimics that of the hanging wall fracture belt on Fig. 1. We have been unable to reproduce the hanging wall fractures outboard of the buckles in models that lack antithetic fractures. These results collectively suggest that antithetic fracturing in the subsurface is a prime cause of the fractures at the surface of the hanging wall.

\section{Discussion}

Our field observations from the KFS are consistent with those of Duffield (1975) and Martel and Langley (2006) although we examined the fault trace tips in more detail.
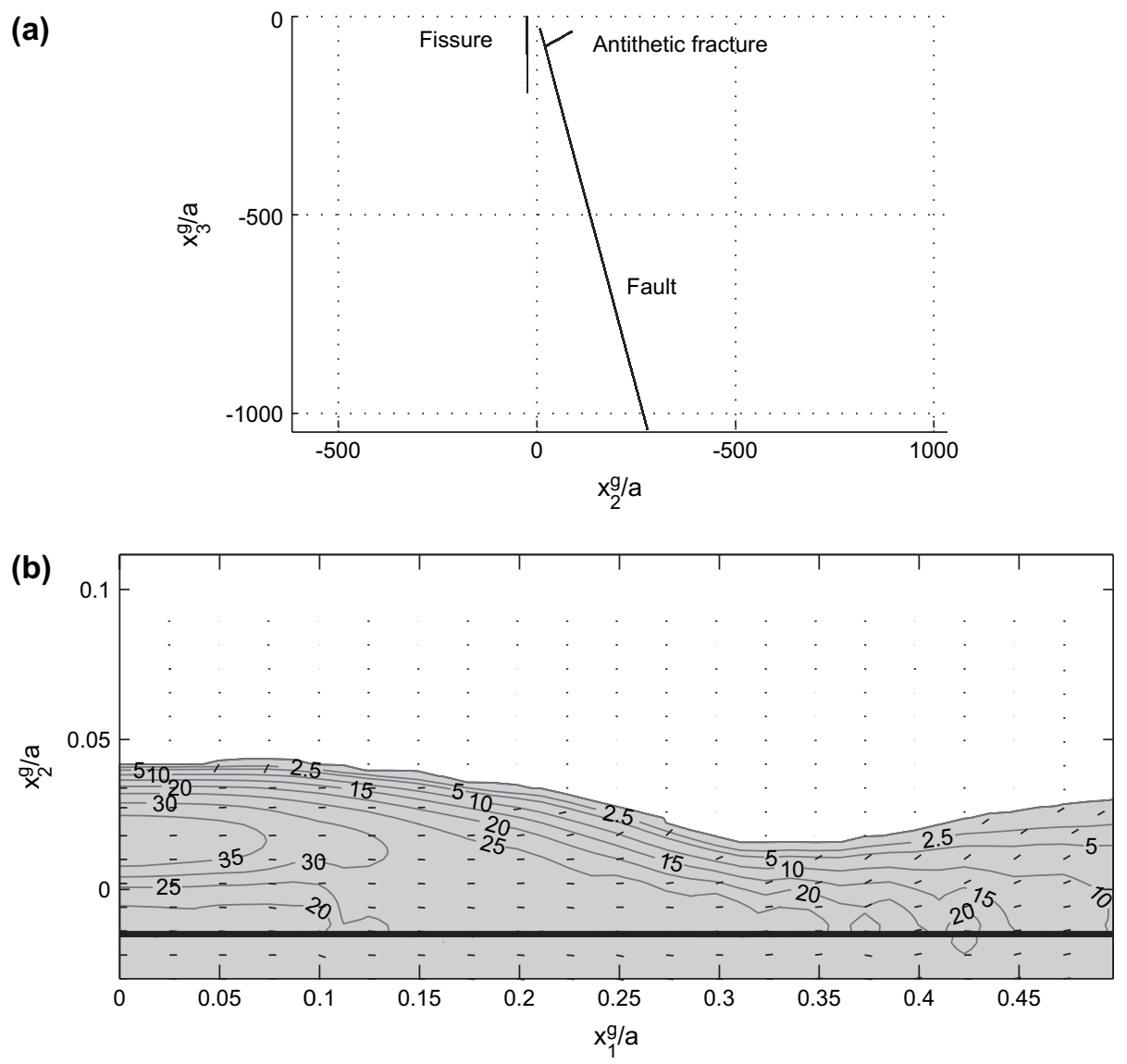

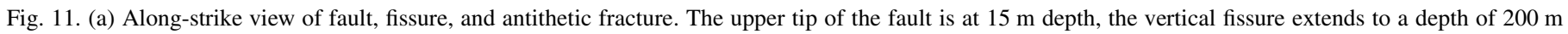

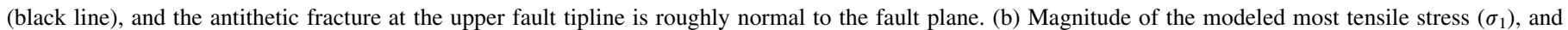
trajectories perpendicular to $\sigma_{1}$ (i.e., orientations of potential opening-mode fractures). 
The consistent and systematic pattern of fractures along the faults indicates that the normal faults of the KFS evolved in a similar way. The general pattern of the structures near the northern fork of the Hopena fault also appears to resemble the pattern along faults in Iceland (Grant and Kattenhorn, 2004), and perhaps along the East African Rift (Acocella et al., 2003).

Our field observations and model results together support the following growth process, which can be divided into a blind fault stage and a breached fault stage (Fig. 12):

(a) As a blind fault propagates up toward the ground surface (Fig. 12a), the surface is flexed. In response, fractures parallel to fault strike open on the footwall, and echelon fractures open along the future scarp. Both sets of fractures grow down from the surface and are discontinuous. Antithetic fractures probably nucleate near the upper part of the fault tipline also.

(b) As the fault tipline nears the surface (Fig. 12b,c), the central limb of the monocline steepens, fractures on the footwall grow longer and wider, and debris stoped from their walls accumulates in them. Buckles develop near the base of the future scarp. Eventually subsurface antithetic fracturing near the still blind tip of the growing fault causes fractures to open at the surface on the hanging wall. (c) Once a normal fault breaches the surface (Figs. 8h and 10h), the stress concentrations shift to the ends of the fault trace. A fault-normal tensile stress concentration develops on the footwall and ahead of the fault trace, with a faultnormal compressive stress concentration developing on the hanging wall. New fissures oblique to the fault trace open both in the footwall and along the line of the fault trace, and new buckles can form near the end of the fault scarp. Previously formed echelon fractures along the projection of the fault trace that strike oblique to the fault at low angles $\left(<40^{\circ}\right)$ slip laterally as the fault trace propagates (Fig. 10h). At the same time, the horizontal stresses along the walls of the fault become compressive. At least initially, this retards the formation of new antithetic fractures in the subsurface of the hanging wall, thus impeding the opening of more fractures at the surface on the hanging wall.

(d) As slip increases along the fault and the scarp increases in height and length, echelon fractures along the scarp and footwall become linked to each other and to the fault, causing the fault trace to become irregular.

Our interpretation, based on the field observations and three-dimensional mechanical analyses, that the observed ensemble of structures reflects the propagation of a normal fault (a)

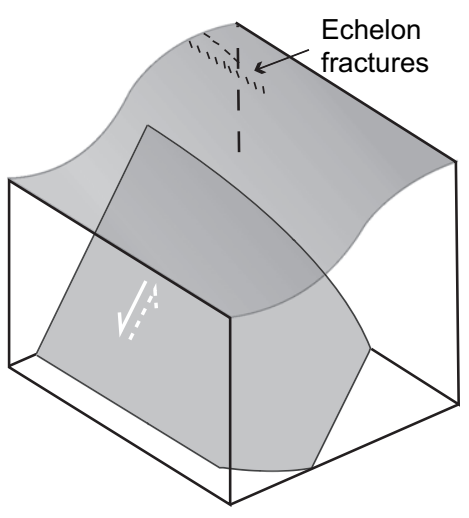

(c)

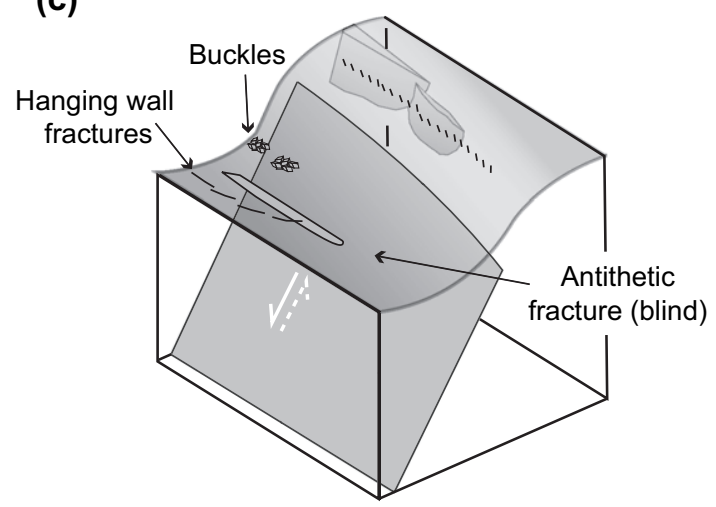

(b)

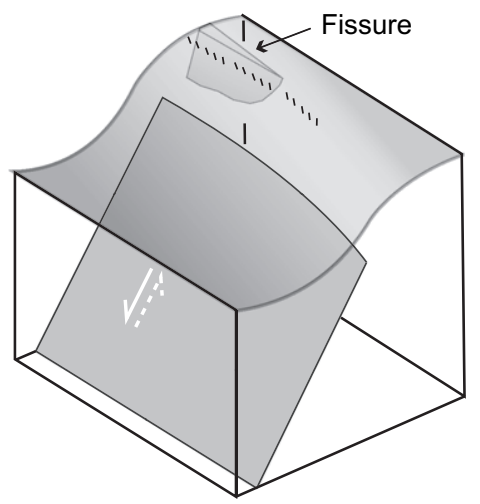

(d)

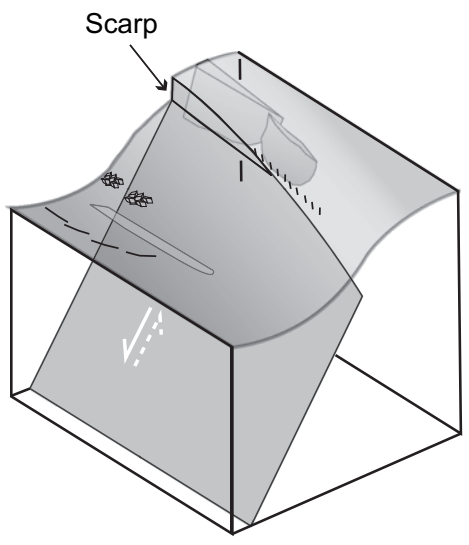

Fig. 12. Cartoon depicting the growth of normal faults. (a) A blind normal fault at depth flexes the surface and fracturing occurs in footwall. (b) Blind normal faults propagates up, and footwall fissures roughly parallel to fault strike open more, propagate along strike, and link. (c) The normal fault propagates further, buckles form at the base of the future scarp, and antithetic fracturing in the subsurface near the upper fault tip induces surface fractures in the hanging wall. (d) The fault breaches the surface, and echelon fractures form at the surface near the tip of the fault trace. 
to the surface is consistent with, but builds upon, the interpretation of Martel and Langley (2006), who relied on two-dimensional analyses. Both sets of findings provide some insight into how damage zones of fractured rock along a normal fault (e.g., Caine et al., 1996) might develop as a result of fault propagation, perhaps analogous to a macroscopic process zone, rather than as a result of abrasion along the fault walls.

The key new contributions of this work pertain to three-dimensional aspects of fault growth. We document systematic along-strike variations in structure towards the end of a normal fault trace, such as the curvature of the belt of hanging wall fractures toward the fault trace tip and the decrease in relative displacement across fractures towards the fault trace end. Our mapping shows that echelon fractures along the fault scarp are a persistent feature and that the structures along the fault are discontinuous along strike, even along a fault scarp only a few meters high. The linkage of such features will cause normal faults to develop a discontinuous trace. Our mapping and mechanical analyses both indicate that fractures and buckles can develop near the fault trace end once the fault breaches the surface. Our results also indicate that certain fractures along normal faults that initially open in response to faulting will tend to slip as the fault grows, some slipping in a normal sense (e.g. the footwall fissures), and others in a strike-slip sense (e.g., fractures near the scarp end). This variation in the sense of slip does not require a change in the regional stresses but can instead occur as a result of local stress changes caused by the growth of the scarp and the propagation of the fault tipline. We expect similar effects could occur along normal faults elsewhere at other scales.

\section{Conclusions}

The Hopena fault displays a systematic set of structures along its trace:

(1) A breached monocline along the scarp;

(2) Pronounced, steep fractures on the footwall;

(3) A belt of echelon fractures along the scarp and past its end;

(4) Buckles at the base of the scarp;

(5) A belt of fractures on the hanging wall that converges towards the end of the fault trace.

This ensemble developed as the tipline of the normal fault propagated up towards the surface, intersected it, and then propagated laterally along the surface. This process, if accompanied by antithetic fracturing in the shallow subsurface, can account for all the aforementioned structures along the fault trace. Our three-dimensional model accounts for features that two-dimensional models of normal faulting in cross section (e.g., Martel and Langley, 2006) cannot account for, such as the echelon nature of the fractures, the along-strike variation in the fracture belts, and fracturing associated with the lateral propagation of the fault trace tip. The discontinuous, irregular character of the normal fault traces is an intrinsic consequence of three-dimensional fault growth and the formation and linkage of echelon fractures along the scarp.

We associate the left-lateral slip along northeast-striking fractures near the east end of the scarp with local stress field changes associated with the lateral propagation of the fault trace tip, rather than reflecting a change in the regional stress field. We expect that our findings for the Hopena fault apply to larger faults as well.

\section{Acknowledgements}

We thank Patience Cowie and, especially, David Healy for their critical reviews of the manuscript. We also thank editor Holdsworth for his stewardship. We are grateful for the support from the US Department of Energy Office of Basic Energy Sciences (Grant No. DE-FG03-85ER15525) and the National Science Foundation (Grant No. EAR05-38334). This is SOEST contribution No. 7063.

\section{References}

Acocella, V., Korme, T., Salvini, F., 2003. Formation of normal faults along the axial zone of the Ethiopian Rift. Journal of Structural Geology 25, 503-513.

Caine, J.S., Evans, J.P., Forster, C.B., 1996. Fault zone architecture and permeability structure. Geology 24, 1025-1028.

Cartwright, J.A., Mansfield, C.S., 1998. Lateral displacement and lateral tip geometry of normal faults in the Canyonlands National Park, Utah. Journal of Structural Geology 20, 3-19.

Cloos, E., 1968. Experimental analysis of Gulf Coast fracture patterns. American Association of Petroleum Geologists Bulletin 52, 420-444.

Crider, J.G., Pollard, D.D., 1998. Fault linkage: three-dimensional mechanical interaction between echelon normal faults. Journal of Geophysical Research 103, 24373-24391.

Duffield, W.A., 1975. Structure and origin of the Koae Fault System, Kilauea Volcano Hawaii. United States Geological Survey Professional Paper 856.

Grant, J.V., Kattenhorn, S.A., 2004. Evolution of vertical faults at an extensional plate boundary, southwest Iceland. Journal of Structural Geology 27, 537-557.

Gudmundsson, A., 1987. Tectonics of the Thingvellir fissure swarm, SW Iceland. Journal of Structural Geology 9, 61-69.

Gudmundsson, A., Bäckström, A., 1991. Structure and development of the Sveinagja graben, Northeast Iceland. Tectonophysics 200, 111-125.

Holland, M., Urai, J.L., Martel, S.J., 2006. The internal structure of fault zones in basaltic sequences. Earth and Planetary Science Letters 248, 286-300.

Kattenhorn, S.A., Pollard, D.D., 2001. Integrating 3-D seismic data, field analogs, and mechanical models in the analysis of segmented normal faults in the Wytch Farm oil field, southern England, United Kingdom. American Association of Petroleum Geologists 85, 1183-1210.

Kaven, J.O., 2004. Normal fault growth in three dimensions. Unpublished MS thesis, University of Hawai'i.

Lipman, P.W., Lockwood, J.P., Okamura, R.T., Swanson, D.A., Yamashita, K.M., 1985. Ground Deformation Associated with the 1975 Magnitude 7.2 Earthquake and Resulting Changes in Activity of Kilauea Volcano, Hawai'i. United States Geological Survey Professional Paper 1276.

MacDonald, G.A., 1957. Faults and monoclines on Kilauea Volcano, Hawaii. Bulletin of the Geological Society of America 68, 269-271.

Martel, S.J., Langley, J., 2006. Propagation of normal faults to the surface in basalt, Koae fault system, Hawaii. Journal of Structural Geology 28, 2123-2143.

Nicol, A., Watterson, J., Walsh, J.J., Childs, C., 1996. The shapes, major axis orientations and displacement patterns of fault surfaces. Journal of Structural Geology 18, 235-248. 
Opheim, J.A., Gudmundsson, A., 1989. Formation and geometry of fractures, and related volcanism, of the Krafla fissure swarm, northeast Iceland. Bulletin of the Geological Society of America 101, 1608-1622.

Peacock, D.J., Sanderson, J., 1996. Effects of propagation rate on displacement variations along faults. Journal of Structural Geology 18, 311-320.

Peacock, D.C.P., Parfitt, E.A., 2002. Active relay ramps and normal fault propagation on Kilauea Volcano, Hawaii. Journal of Structural Geology 24, 729-742.

Pollard, D.D., Delaney, P.T., Duffield, W.A., Endo, E.T., Okamura, A.T., 1983. Surface deformation in volcanic rift zones. Tectonophysics 94, 541-584.

Rippon, J.H., 1985. Contoured patterns of throw and hade of normal faults in coal measures (Westphalian) of northeast Derbyshire. Proceedings of Yorkshire Geological Society 45, 147-161.

Rubin, A.M., Pollard, D.D., 1987. Origin of blade-like dikes in volcanic rift zones, in: Decker, R.W., Wright, T.L., Stauffer, P.H. (Eds.), Volcanism in Hawaii. United States Geological Survey Professional Paper 1350, pp. 1549-1570.
Swanson, D.A., Duffield, W.A., Fiske, R.S., 1976. Displacement of the south flank of Kilauea Volcano: the result of forceful intrusion of magma into rift zones. Unites States Geological Survey Professional Paper 963.

Thomas, A.L., 1993. Poly3D: a three-dimensional, polygonal element, displacement discontinuity boundary element computer program with applications for fractures, faults, and cavities in the Earth's crust. MS thesis, Stanford University.

Willemse, J.M., 1997. Segmented normal faults: correspondence between threedimensional mechanical models and field data. Journal of Geophysical Research 102, 675-692.

White, I.R., Crider, J.G., 2006. Extensional fault-propagation folds: mechanical models and observations from the Modoc Plateau, northeastern California. Journal of Structural Geology 28, 1352-1370.

Wolfe, E.W., Morris, J., 1996. Geologic map of the island of Hawaii. United States Geological Survey Map I-2524-A. 